Article

\title{
Spiritual Crisis as a Unique Causal Predictor of Emotional and Characterological Impairment in Atheists and Agnostics: Numinous Motivations as Universal Psychological Qualities
}

\author{
Ralph L. Piedmont ${ }^{1, *}$, Jesse Fox ${ }^{2} \mathbb{D}$ and Marion E. Toscano ${ }^{3}$ \\ 1 Center for Professional Studies, 9603 Deereco Road, \#5334, Timonium, MD 21094, USA \\ 2 Department of Counselor Education, Stetson University, DeLand, FL 32723, USA; jfox2@stetson.edu \\ 3 Natural \& Health Sciences and Education Faculty, Mount Mary University, Milwaukee, WI 53222-4597, USA; \\ toscanom@mtmary.edu \\ * Correspondence: mrmagic328@comcast.net
}

Received: 31 July 2020; Accepted: 13 October 2020; Published: 24 October 2020

check for updates

\begin{abstract}
While there is a tremendous literature documenting the positive value of religious and spiritual (R/S) constructs on an array of psychosocial outcomes (e.g., health, resilience, coping ability), Spiritual Crisis (SC) reflects the negative side of the numinous in a way that stresses the value and importance of $\mathrm{R} / \mathrm{S}$ constructs for psychological functioning. This study examined whether numinous constructs are more relevant to theists or represent universal psychological qualities. Using an MTurk-based sample comprising both theists and atheists ( $\mathrm{N}=1399 ; 800$ women and 595 men, four gave no response), the predictive ability of SC on both affective and characterological distress was examined using both regression and SEM analyses. The results indicated that both theists and atheists understood the numinous in similar ways and that scores on SC were of equal incremental predictiveness for both groups. SEM analyses supported the causal model that understood SC to be a unique and independent (from the personality domains of the Five-Factor Model) predictor of these clinical outcomes. These findings stress the value of the numinous for understanding all clients and that psychological assessment needs to systematically address numinous constructs in order to ensure comprehensive treatment of psychological impairment.
\end{abstract}

Keywords: spiritual crisis; numinous motivations; numinous motivation inventory; atheists

\section{Introduction}

"Indeed, if religion is a human universal, then we should expect to see it everywhere, reinvented and repackaged in secular guises all around us. This renders the scientific study of 'religion' more difficult but also much more compelling". (Grassie 2010, p. 47)

Religious and Spiritual Crises (RC/SC) are very important constructs in the psychology of religion and spirituality (PRS) ${ }^{1}$. While there is a tremendous literature documenting the positive value of religious and spirituality (R/S) constructs on an array of psychosocial outcomes (e.g., health,

1 The constructs of "religious crisis" (RC) and "spiritual crisis" (SC) are related terms in that both capture feelings of rejection and inadequacy from a larger, transcendent reality. However, there are important differences between the two. Piedmont (2020) and Piedmont and Wilkins (2020) have proposed that spirituality and religiousness, while strongly related, represent different psychological constructs. Spirituality represents an intrinsic, operant source of motivation that is very similar to other personality traits; it is an inherited quality. Religiousness, on the other hand, represents a learned set of values and beliefs, something that is acquired through socialization. While both are sources of motivation, they are mediated by 
resilience, coping ability; Koenig et al. 2001; Plante and Sherman 2001), SC reflects the negative side of the numinous in a way that stresses the value and importance of $\mathrm{R} / \mathrm{S}$ constructs for psychological functioning. SC represents an extreme level of existential condemnation-the personal belief that an individual is unworthy or of little value within the larger scheme of life itself-that one's existence has completely failed to be of benefit to life. The resulting feelings of emptiness and existential rejection can lead to tragic consequences, like suicide, depression, and characterological impairments (Fox and Piedmont 2020; Piedmont 2017; Piedmont et al. 2007; Piedmont and Wilkins 2020). The profound impact of SC on functioning raises an important question, "Is SC an issue only for those who believe in the existence of a God or is there something more fundamental, and universal, that is operating?" If SC is only relevant for theists, then the construct represents a limited dynamic that is merely an epiphenomenon of religious belief. However, if SC represents a more fundamental, universal quality, then an exciting possibility exists for both expanding our understanding of intrapsychic dynamics as well as identifying a new, broad causal pathway to psychological impairment. The purpose of this report is to address this question head-on by examining the utility and predictive power of this construct in samples of both theists and non-theists.

\subsection{The Role of the Numinous in the Psychology of Religion and Spirituality (PRS)}

\subsubsection{God-Centric Approach}

The dominant model for understanding $R / S$ constructs is God-centric, in that $R / S$ variables are only relevant and important to individuals who are theists. The role of God is important to this perspective because without such a belief, R/S constructs have little value or relevance. Further, many constructs are based on theological traditions and perspectives grounded specifically in the Western religious context of mono-theism and the Abrahamic traditions (Judaism, Christianity, and Islam; e.g., Christian Experience Inventory (Alter 1989); God Image Inventory (Lawrence 1991)). While this approach may provide a clear direction for identifying qualities and behaviors that may be of importance to understanding $\mathrm{R} / \mathrm{S}$ sentiments, it does serve to parochialize the larger implications of these constructs.

Reinforcing this approach is the assumption that spirituality emerges out of religion, making it a facet of religious belief (Pargament 1999). Thus, at the center of R/S research is a belief in a transcendent God and it is the personal attachment to this God that creates the spiritual and religious sentiments of the person. Pargament (1999, p. 12) has defined spirituality and religiousness as "a search for the sacred." What is essential to this definition, according to Pargament, is the role of the sacred in making motivations spiritual, "At the heart of the sacred lies God, divine beings, or a transcendent reality" (Pargament 2007, p. 33). This definition makes a distinction between personal ethics or guiding philosophies of life and R/S beliefs: There are those motivations that are spiritual because of their God-centric perspective and those that are not spiritual because God is not involved (see also Hill et al. 2000, p. 65).

This approach prevents the PRS from succumbing to a vague, boundaryless, spiritualism where anything is seen as spiritual. This empties the construct of any practical meaning and impedes its differentiation from something that is not spiritual. For instance, veganism can be part of spiritual outlook on life, but veganism by itself is not by definition spiritual. Moreover, by differentiating a sacred core (the essence of spirituality) vs. a sacred ring (symbols of the sacred core, i.e. religions), it makes the study of the PRS less confined to one religious perspective and opens up the possibility of

different psychological systems (see Piedmont et al. (2009) for data which support this view). Practically, these constructs ought to predict similar outcomes for people. The difference, though, is that RC examines this sense of rejection as a result of one's abandonment from the God of one's understanding and/or from one's religious community. SC understands this rebuff as stemming from a personal feeling of condemnation and rejection by one's own sense of ultimate value and worthiness. The former construct requires a belief in a God while the latter does not. 
multiple, valid perspectives. Though not entirely universal, it is less exclusive than researching the sacred through the lens of one religion or assuming a priori privilege of one tradition (e.g., Christian).

There are, at the same time, several limitations to this perspective. First, it makes PRS a rather boutique area of research because of its focus on a very select group of people: Those who are theists or those very closely associated like polytheists. While this includes a large number of people, it does exclude people of faith from religions that do not necessarily contain a Western concept of "God" (e.g., Shintoists, Buddhists, Janists, etc.). This perspective also minimizes nontheists and nonreligious individuals, who are also mostly unincluded in the research literature (Leach and Sato 2013). There is the perspective that without a notion of God, there is no spirituality, thus non-believers cannot avail themselves of the benefits of spirituality. It is as if such individuals are unable to create meaning systems that are as developed and psychologically useful as those of believers. Second, this approach faces a crisis of utility according to the secularization hypothesis, which states that as individuals and societies embrace secularization (non-religious political institutions, industrialization, science, and modern medicine) religions will lose their relevance (Voas 2019; Voas and Chaves 2016). Is the implication of secularization, then, that with people moving out of religious affiliations or not acquiring them (Pew Research Center 2015), mean that the PRS is therefore less salient and of increasingly limited value for psychotherapy? This question strikes to the heart of the PRS conceptualized from the perspective of the God-Centric Approach and poses a significant threat to the utility of the field.

Finally, by casting our constructs as reflecting God-based theologies, there are real ethical concerns as to whether social scientists are being cast as shills for religion. For example, when research shows a positive association between religious attendance and better blood pressure levels (e.g., (Koenig et al. 2001)), should therapists recommend to their hypertensive patients to attend church services? Should therapists encourage atheists and other nonbelievers to become believers in order to improve their health status? While some in this field may find this useful (e.g., Koenig 1999), it may create ethical issues centering on coercion and discrimination (Sloan et al. 2001). Even when the practice of counseling and psychotherapy includes a respect for worldview differences between clinicians and clients, such as spiritually integrated psychotherapy (Pargament 2007), a God-centric approach does not offer a framework for applying the psychological benefits of religion beyond group level interpretation. While this perspective may be less coercive than the one above, findings from research using this approach are really ethically limited to applications with clients who are followers of religions. It makes no ethical sense, for instance, to assess religious coping in a client who is atheist, even though a strong research base exists demonstrating the utility of religious coping for promoting psychological health.

\subsubsection{The Universal Approach}

There is a growing acknowledgement that R/S issues are really the particular expressions of universal existential human motivations (Grassie 2010; Piedmont and Wilkins 2020). From this perspective, all people confront a similar array of issues surrounding personal needs for meaning, worthiness, and finitude (Tillich [1952] 2000). As such, spiritual issues and concerns are addressed by all people, although the responses to these concerns may be quite varied (Comte-Sponville 2006; Grassie 2010). Piedmont (2015); Piedmont and Wilkins (2020) has developed an ontological model that outlines the origins, role, and functioning of numinous dynamics. Numinous motivations are those psychological qualities that underlie peoples' interest in religious and spiritual issues. Numinous constructs are what propel the "search for the sacred" noted by Pargament (2007). This ontological model stresses the unique, exceptional nature of the numinous and is based on three observations: (a) R/S are universal aspects of human functioning, being significant factors in all cultures and across all ages; (b) there are individual differences in the extent to which individuals are sensitive to these qualities, indicating that these qualities are both inherent to people and evidence individual-difference properties akin to other personality-type constructs; and (c) R/S dynamics are unique to the human species; there are no animal models for these constructs. The existence of these qualities is rooted in 
the core of our humanity. Piedmont argued that R/S constructs (i.e., numinous motivations) find their origins within the neo-cortex, that aspect of brain functioning that is responsible for the unique cognitive powers that characterize humans. For Piedmont, the numinous represents those psychological qualities that uniquely define the human species (Piedmont n.d.; Piedmont and Wilkins 2020). These motivators are what make R/S so important to all humans. It also provides an understanding of R/S constructs that promotes interpretive value and clinical significance.

Piedmont identified three core numinous motivations: Infinitude (I; our need to find personal durability for our strivings in life), Meaning ( $\mathrm{M}$; the need to develop purpose and direction for our lives), and Worthiness (W; finding personal acceptance of self within a transcendent perspective). What is important is that all of these qualities are strictly psychological in nature. There is no need for appeal to specific theologies or religious denominations in order to understand the value and role of these constructs. As noted above, our numinous motivations are what make $\mathrm{R} / \mathrm{S}$ so important to us as a species. Having this ontological model provides direction and clarity to defining what is and is not a R/S construct (see Piedmont and Wilkins (2020) for a complete presentation of this model and its clinical applications).

The value of this universal approach is that it offers the opportunity to expand the social science's understanding of the mental world because these qualities operate independently of other aspects of the psychic system (e.g., personality). As a new dimension of functioning, their role in psychological process may provide new perspectives on disorders that seem resistant to standard interventions. There may also be the potential for new types of interventions based on the numinous that can be useful for addressing a wide array of psychosocial issues.

\subsection{Developing and Applying Universal Numinous Constructs}

Piedmont and Wilkins (2020) presented a rigorous empirical model for developing numinous constructs which is based on nine assumptions about the underlying nature of these motivations. The end goal of this process is the creation of a psychological scale that contains concepts and perspectives found in many religions but presented using non-theistic language. Further, such a scale would be independent of already existing psychological constructs and universally relevant. The non-denominational language in scale items makes the completion of the measure easier and more appropriate for non-theists. Working from this perspective, Piedmont (2017, in press) has developed the Numinous Motivation Inventory (NMI) which he considers to be a second-generation measure of the numinous. Based on findings from previous research, the NMI attempts to provide a more accurate assessment of the numinous with consequently higher predictive validities. As a measure of universal motivations, scores on the scale ought to be equally reliable and valid across denominational status. The emerging data on this scale appears to support the value of both the ontological and empirical models upon which it is based (Piedmont n.d.; Piedmont and Wilkins 2020).

Of particular interest to this study is the numinous facet of Worthiness (W). Piedmont (2017, p. 12) provided the following description of this construct:

While we recognize our own imperfections and failings, ultimately each of us assesses our worth and value within the entire universe as we conceive and understand it. This creation of ours exists as its own reality that calls on us to make a statement of our own worth and value. In return we seek acceptance as being worthy. We seek acceptance from the totality of our entire sense of meaning, despite our own perceived unacceptability. There is security in feeling worthy, there is emptiness in feeling condemned.

For those who score high on this scale, there is a feeling of personal security and comfort in being which leads to a larger, overall sense of well-being. For those who score low, there is an experience of existential condemnation that is difficult to overcome. Piedmont and Wilkins (2020) provided data showing how low scores are associated with suicidal ideation and continual thoughts of death. Worthiness represents the core qualities of what is commonly referred to as religious crisis (Piedmont 
2020) or spiritual struggle (Fox and Piedmont 2020). This construct has shown itself to be a very powerful predictor of emotional distress and maladjustment (Ano and Vasconcelles 2005; Exline 2013; Exline et al. 2000; Wilt et al. 2016).

Working with the Religious Crisis (RC) scale from Piedmont's first generation measure of the numinous, the Assessment of Spirituality and Religious Sentiments (ASPIRES) scale (Piedmont 2020), Piedmont et al. (2007) demonstrated that SC was a significant predictor of characterological impairment, even after the predictive effects of the domains of the Five-Factor Model (FFM; Digman 1990) of personality were partialed out. Fox and Piedmont (2020) examined the predictive value of RC in regards to the experience of depression, anxiety, and stress. Several important findings were observed. First, $\mathrm{RC}$ was a significant, unique predictor of these measures of affective dysphoria; it evidenced significant incremental predictive power over the FFM domains. This suggested that RC and Neuroticism were complementary predictors of emotional distress. Second, using structural equation modeling, Fox and Piedmont evaluated three different causal models that varied the role of RC on the outcomes (see Figure 1). The results indicated that understanding $\mathrm{RC}$ as an independent, causal agent was found to be the best model.

Two important conclusions were drawn from these data. First, the numinous represents a human-specific motivation that is independent of other, evolved psychological drives. It also indicated that there may be a second pathway leading to psychological problems other than Neuroticism. The numinous may have a significant role to play in creating wellness and distress. Second, the causal modeling analysis demonstrated that the reason why RC is correlated with such dysphoria is because it serves as an independent causal input into the psychic system. The field of PRS has never provided any explanation of the nature of its constructs (e.g., Piedmont 2014), leaving critics to see them as merely stand-in variables for already existing psychological constructs (Funder 2002; Buss 2002; Van Wicklin 1990). These findings showed such perspectives as missing the essential nature of these motivations.

\subsection{The Current Study}

The data to date have indicated that numinous constructs are independent of existing psychological motivations and operate as causal agents in the psychological system. There is one further essential test for Piedmont's ontological model: Are numinous motivations really universal? An extensive literature has already emerged demonstrating the cross-cultural and cross-religious generalizability of numinous motivations (e.g., Chen 2011; Joshanloo 2012; Piedmont and Leach 2002; Rican and Janosova 2010); numinous constructs have been found to be reliable and valid with Christians, Jews, Muslims, Hindus, and other indigenous religious groups. However, all of these studies included religious believers. It could be argued that the conceptual and theological differences between these faith traditions are not as large as one would believe them to be (Grassie 2010). Therefore, any belief in a transcendent, eternal being/reality brings with it exposure to similar numinous concepts.

The current study provides a more rigorous test of the universality of numinous motivations: An examination of the numinous with atheists and agnostics. These are individuals who are not members of any religious tradition. While some may have been denominationally affiliated at some point in their pasts and therefore have some familiarity with numinous concepts, as atheists/agnostics these individuals have rejected current religious ideas and practices, seeing them as being irrelevant and/or sophistic. These individuals are quite distinct from believers who have made a personal commitment to these beliefs and practices and the transcendent perspective they proffer. Therefore, if the numinous is very much a theologically-derived concept, then it should hold little value for atheists and agnostics. If this is true, then we would expect to find the factor structure of the NMI to be different with this group than with believers. We would further expect that the NMI would be of little predictive value for atheists in comparison to believers and would evidence no causal predictiveness. However, if the numinous is truly universal, then atheists and believers alike ought to understand the NMI constructs similarly and scores ought to predict the outcomes with comparable effect sizes. Finally, the numinous would evidence itself as being an independent causal predictor of 
both affective and characterological impairment for both groups. This will be done by demonstrating that Worthiness will evidence significant, incremental predictive power over the dimensions of the Five-Factor Model (FFM) of personality (Digman 1990; McCrae 2010). These dimensions have been shown to comprehensively represent those individual difference variables traditionally considered to be personality (Piedmont 1998).

Finding evidence of universality will bring a sense of parsimony to research in this area by demonstrating that all R/S constructs (whether denominationally based or not) have a common foundation in a core set of motivations. Further, because numinous motivations are independent of established individual-differences variables, it may represent a whole new class of psychological processes in need of exploration and development. Because the numinous is a core aspect of functioning that is unique to humans, plumbing its depths promises to yield new insights into our ultimate nature and the identification of new modalities for encouraging change, growth, and resilience.

\section{Method}

\subsection{Participants}

Participants were selected from the normative sample of the NMI (Piedmont 2017) which consisted of 1626 individuals. For the purposes of this study these individuals were assigned to either the believer or atheist/agnostic groups based on their religious affiliation. Not included were those who indicated they were Buddhists, Pagans or Earth-based, or were spiritual but not religious $(n=227)$, resulting in an overall usable sample of 1399 volunteers (800 women and $595 \mathrm{men}, 4$ gave no response) ranging in age from 18 to $81(M=37.15, S D=12.02)$. The sample was restricted to just US residents for whom English was their first language. Concerning ethnicity, $75 \%$ were Caucasian, $7 \%$ were African-American, 7\% Asian, 6\% Hispanic, 3\% Multiethnic, with the remaining 2\% being American Indian, Arabic, Native Hawaiian, and other. Regarding education level, $75 \%$ had a college degree or college experience; $17 \%$ had a graduate or post-graduate degree, $8 \%$ had a high school diploma and less than $1 \%$ had less than high school education. Concerning occupation $12 \%$ of the sample were in education, with the remaining participants coming from a wide array of careers (e.g., $11 \%$ health care, $12 \%$ information technology, $7 \%$ administration, and $6 \%$ retail). The Believer (BEL; $n=908$ ) and Atheist/Agnositic (A/A; $n=491)$ groups were composed as follows: In the BEL group, there were 824 Christians (e.g., Catholics, Baptists, Episcopal, Evangelical, Lutheran, Pentecostal, Presbyterian), 22 Hindus, two American-Indians of indigenous faith, 27 Jews, 18 Muslims, and 20 who indicated "Other Faith Tradition." In comparing these two groups, no significant difference was noted on an education level. However, there were differences in terms of age (A/A $M=34.36$ vs. BEL $M=38.65 ; t(1397)=$ $-6.46, p<0.001)$ with the A/A group being slightly younger; gender $\left(\chi^{2}(1 ; N=1395)=8.99, p<0.003\right)$ with more women than expected in the BEL group and more men in the A/A group; and ethnicity $\left(\chi^{2}(1 ; N=1399)=29.05, p<0.001\right)$ with more African-Americans in the BEL group than expected and more Caucasians in the A/A group.

\subsection{Measures}

\subsubsection{The International Personality Item Pool-50 (IPIP-50)}

Developed by Goldberg (1992) is a 50-item inventory of the FFM of personality. The scale measures each dimension of the FFM using 10 items, including (a) Emotional Stability (ES), (b) Extraversion (E), (c) Imagination (Openness; O), (d) Agreeableness (A), and (e) Consciousness (C). Participants read each statement and respond by indicating how it describes them from very inaccurate (1) to very accurate (5). The IPIP-50 is in the public domain and has demonstrated comparable psychometric qualities to commercial inventories of the FFM (Goldberg et al. 2006; Mlačić and Goldberg 2007). Alpha coefficients for the current study are reported in Table 1. 


\subsubsection{The Depression, Anxiety, and Stress Scale-21 (DASS-21)}

Developed by (Lovibond and Lovibond 1995; Brown et al. 1997), the Depression, Anxiety, and Stress Scale-21 (DASS-21) is a brief measure of symptoms common to psychological distress. The instrument consists of three factors (depression, anxiety, and stress) comprised of seven items emblematic of each form of psychological distress. Participants read through each symptom and respond from "Did not apply to me at all" (0) to "Applied to me very much or most of the time" (3) over the course of the previous week. In a non-clinical sample of the U.S. general population, Sinclair et al. (2012) reported the following means and standard deviations for each scale of the DASS-21: Depression $=5.70(8.2)$, Anxiety $=3.99$ (6.3), Stress $=8.12$ (7.6), and Total Score 17.80 (20.2). Alpha coefficients for the current study are reported in Table 1.

\subsubsection{Numinous Motivation Inventory (NMI)}

Developed by Piedmont (2017) this 22-item scale assesses numinous qualities of the individual. There are three facet scales: Infinitude (I), an intrinsic drive to acquire substance and continuity in one's life in the face of one's own mortality (item: I believe that this life is only one stage in a larger, eternal process); Meaning (M), captures the extent to which individuals have created an ultimate sense of personal meaning that they place their ultimate trust in and towards which they devote their lives (item: I am guided by my personal philosophy and/or faith); Worthiness (W), the extent to which individuals experience acceptance and worth, despite personal foibles and imperfections, from their perceeived understanding of life (item: I value myself). Items are responded to on a 1 (Strongly Disagree) to 5 (Strongly Agree) Likert-type scale. Items are balanced to control for acquiescence effects. Piedmont (2017) demonstrated the independence of these scales from established personality dimension (e.g., the Five-Factor Model of Personality (FFM) dimensions), their incremental validity over the FFM in predicting an array of psychosocial outcomes (e.g., resilience, self-compassion, positive and negative affect). Reliabilities for this scale are presented in Table 1.

\subsubsection{Personality Inventory for the DSM-5 Brief Form (PID-5)}

Developed by Krueger et al. (2012), this 25-item scale is intended to capture personality-related dimensions that underlie the Diagnostic and Statistical Manual-5's (DSM-5; American Psychiatric Association 2013) personality disorders (PDs). Items are responded to on a 0 (very false) to 3 (very true) Likert-type scale. There are five dimensions assessed: Negative Affect (NA): The frequent and intense experiences of high levels of negative emotions; Detachment (Detach): The avoidance of socioemotional experiences including both social withdrawal and restricted affective experiences; Antagonism (Antag): Tendency of individuals to put themselves at odds with others; Disinhibition (Inhib): An orientation towards immediate gratification and impulsiveness that is driven by thoughts, feelings, and external stimuli; and Psychoticism (Psychotic): The expression of culturally incongruent odd, eccentric, or unusual behaviors and cognitions. Krueger et al. (2012) provide initial evidence of validity. Reliabilities for these scales in the current study are presented in Table 1.

\subsection{Procedure}

Loyola University Maryland's Institutional Research Board approved this study. All of the measures were digitized and loaded into a Qualtrix Survey. That survey was then uploaded onto Amazon's MTurk platform, an online platform for soliciting research participants. The data presented here are part of a larger study (Piedmont 2017). Participants were paid $\$ 1.25$ for completion of the survey, with the money being directly credited to their respective Amazon accounts by Amazon. For the purposes of this study, we requested only US-based workers for whom English was their first language. The presentation of the measures was counterbalanced to control for any order effects. Further, three attention check items were included. Any participant who failed to select the appropriate response for any of these items was deleted from the final data set. 


\section{Results}

The data were screened for missing data and there were none. This is because each item had to be completed before one could move on to the next. Moreover, for workers to be paid, they are required to answer all items. Data were then analyzed for multivariate outliers using procedures outlined by Tabachnick et al. (2007) and no cases were identified. Examinations for univariate outliers and non-normal distributions indicated that the data were appropriate for parametric analyses.

\subsection{Descriptive Statistics}

Table 1 provides the descriptive statistics across all scales separately by belief group. Mean level scores on the IPIP-50 are consistent with other US samples (e.g., Robertson et al. 2017), although the current sample is slightly lower on Extraversion. Alpha reliabilities for these scales were comparable to those found by Robertson et al. Scores on the PID-5 can range from 0 to 15, thus the scores observed in this sample are in the middle of that range. Values this high indicate some minor levels of distress. Alphas are all consistent with previous data. Scores on the DASS appear slightly higher than college students (e.g., Fox and Piedmont 2020), paralleling the PID-5 results, suggesting higher levels of emotional distress. Alphas are consistent with previous studies.

A comparison of mean level scores across the two belief groups indicated significant differences on all scales. As such, Cohen's $d$ values are reported as the basis for understanding these differences. According to Cohen (1987) effect size interpretations for $d$ are $0.20=$ small, $0.50=$ medium, and $0.80=$ large. As can be seen in Table 1, all but two differences fall in the "small" range. Thus, the observed differences can be attributed more to sample size than to any substantive factor. The exceptions are found on the NMI scales of Infinitude and Worthiness. Here, there are large differences between the two groups, with the A/A group scoring lower. Interestingly, the Worthiness scale shows only a small difference effect. In terms of Worthiness, the item content may appear more personally relevant than the other two scales.

Table 1. Descriptive Statistics by Faith Orientation and Overall Alpha Reliabilities for Study Variables.

\begin{tabular}{|c|c|c|c|c|c|c|}
\hline \multirow[t]{2}{*}{ Scale } & \multicolumn{2}{|c|}{$\begin{array}{l}\text { Atheists/Agnostics } \\
\quad(n=491)\end{array}$} & \multicolumn{2}{|c|}{$\begin{array}{l}\text { Believers } \\
(n=908)\end{array}$} & \multirow{2}{*}{$\begin{array}{c}\text { Cohen's } \\
d\end{array}$} & \multirow[t]{2}{*}{$\alpha$} \\
\hline & $M$ & $S D$ & $M$ & $S D$ & & \\
\hline \multicolumn{7}{|l|}{$I P I P-50$} \\
\hline Emotional Stability & 31.68 & 9.53 & 33.89 & 9.10 & 0.24 & 0.91 \\
\hline Extraversion & 27.34 & 9.03 & 28.98 & 8.68 & 0.19 & 0.90 \\
\hline Openness & 38.43 & 6.40 & 37.35 & 6.55 & 0.17 & 0.83 \\
\hline Agreeableness & 37.27 & 7.42 & 39.33 & 6.67 & 0.30 & 0.87 \\
\hline $\begin{array}{c}\text { Conscientiousness } \\
\text { NMI }\end{array}$ & 36.21 & 7.24 & 37.27 & 7.19 & 0.15 & 0.85 \\
\hline Infinitude & 20.04 & 7.70 & 31.69 & 7.00 & 10.61 & 0.94 \\
\hline Worthiness & 34.51 & 8.38 & 36.94 & 7.19 & 0.32 & 0.93 \\
\hline $\begin{array}{c}\text { Meaning } \\
\text { PID-5 }\end{array}$ & 11.42 & 3.73 & 17.47 & 4.59 & 10.41 & 0.85 \\
\hline Negative Affect & 10.71 & 3.63 & 10.09 & 3.62 & 0.17 & 0.85 \\
\hline Detachment & 9.98 & 30.47 & 8.89 & 3.37 & 0.32 & 0.81 \\
\hline Antagonism & 8.07 & 3.02 & 7.70 & 2.94 & 0.12 & 0.79 \\
\hline Disinhibition & 8.46 & 3.41 & 8.00 & 3.25 & 0.14 & 0.81 \\
\hline $\begin{array}{l}\text { Psychotic } \\
\text { DASS }\end{array}$ & 9.16 & 3.38 & 8.65 & 3.47 & 0.15 & 0.82 \\
\hline Stress & 11.90 & 9.47 & 10.38 & 9.04 & 0.17 & 0.90 \\
\hline Anxiety & 7.64 & 8.66 & 7.04 & 8.02 & 0.07 & 0.88 \\
\hline Depression & 11.33 & 10.92 & 8.40 & 9.36 & 0.29 & 0.93 \\
\hline Total Score & 30.87 & 26.66 & 25.82 & 24.34 & 0.20 & 0.95 \\
\hline
\end{tabular}

IPIP-50 = International Personality Item Pool, FFM 50 item version; NMI = Numinous Motivation Inventory; PID-5 = Personality Inventory for DSM-5; DASS = Depression, Anxiety, and Stress Scale. 


\subsection{Factor Structure}

Given the mean level differences between the two belief groups on the NMI, the question arises as to whether the groups understand the items to the scales in similar ways. To examine this, the NMI items for each group were subjected to a principal components analyses where three factors were extracted and obliquely rotated. Differences in factor structure would indicate that the two groups understand the items in psychologically different ways. Table 2 provides the pattern loadings for the two samples.

Table 2. Comparison of the pattern loadings for the Numinous Motivation Inventory (NMI) Items between atheists/agnostics and other faith traditions.

\begin{tabular}{|c|c|c|c|c|c|c|c|}
\hline \multirow{2}{*}{ NMI Item } & \multicolumn{2}{|c|}{ Factor 1} & \multicolumn{2}{|c|}{ Factor 2} & \multicolumn{2}{|c|}{ Factor 3} & \multirow{2}{*}{ Congruence Coefficients } \\
\hline & A/A & BEL & A/A & BEL & A/A & BEL & \\
\hline $\mathrm{I} 1$ & 0.74 & 0.84 & 0.06 & 0.06 & -0.11 & -0.16 & 1.00 \\
\hline $\mathrm{I} 2$ & 0.89 & 0.83 & 0.05 & 0.09 & -0.11 & 0.01 & 0.99 \\
\hline $\mathrm{I} 3$ & 0.81 & 0.75 & 0.15 & 0.24 & -0.14 & 0.01 & 0.98 \\
\hline I4 & 0.88 & 0.87 & 0.06 & 0.06 & -0.13 & -0.03 & 0.99 \\
\hline I5 & 0.84 & 0.68 & -0.04 & 0.05 & 0.11 & 00.30 & 0.96 \\
\hline I6 & 0.82 & 0.56 & -0.07 & -0.07 & 0.09 & 0.29 & 0.93 \\
\hline I7 & 0.77 & 0.52 & -0.06 & 0.02 & 0.17 & 0.40 & 0.90 \\
\hline I8 & 0.66 & 0.41 & -0.11 & 0.05 & 0.19 & 0.48 & 0.83 \\
\hline $\mathrm{W} 1$ & 0.06 & 0.18 & 0.80 & 0.75 & -0.06 & -0.12 & 0.98 \\
\hline W2 & -0.02 & 0.09 & 0.84 & 0.79 & 0.07 & -0.07 & 0.98 \\
\hline W3 & 0.06 & 0.07 & 0.81 & 0.81 & -0.03 & -0.03 & 1.00 \\
\hline W4 & -0.04 & -0.05 & 0.84 & 0.81 & -0.02 & -0.03 & 1.00 \\
\hline W5 & 0.00 & 0.05 & 0.79 & 0.75 & -0.07 & -0.02 & 1.00 \\
\hline W6 & 0.03 & 0.02 & 0.85 & 0.78 & -0.01 & 0.02 & 1.00 \\
\hline W7 & -0.02 & -0.05 & 0.80 & 0.78 & 0.05 & 0.03 & 1.00 \\
\hline W8 & 0.03 & 0.06 & 0.82 & 0.78 & 0.00 & 0.05 & 1.00 \\
\hline W9 & -0.02 & -0.17 & 0.80 & 0.78 & 0.16 & 0.23 & 0.98 \\
\hline M1 & -0.17 & 0.21 & 0.13 & 0.01 & 0.73 & 0.71 & 0.86 \\
\hline M2 & -0.05 & 0.08 & -0.04 & 0.04 & 0.80 & 0.81 & 0.98 \\
\hline M3 & 0.20 & -0.03 & -0.28 & 0.10 & 0.56 & 0.84 & 0.90 \\
\hline M4 & -0.01 & 0.18 & 0.03 & 0.08 & 0.70 & 0.70 & 0.96 \\
\hline M5 & 0.23 & -0.12 & 0.06 & 0.11 & 0.42 & 0.55 & 0.76 \\
\hline Congruence Coefficients & \multicolumn{2}{|c|}{0.94} & \multicolumn{2}{|c|}{0.99} & \multicolumn{2}{|c|}{0.95} & 0.96 \\
\hline
\end{tabular}

W = Worthiness; I = Infinitude; M = Meaning; A/A—Atheists/Agnostics; BEL = Believers. Note. Loadings greater than or equal to 0.40 are in bold.

Two points of interest emerge from Table 2. First, the three-factor putative structure to the NMI is clearly recovered in both groups. Interestingly, the only infelicity in these data are found for the Believer group where two Infinitude items have secondary loadings on the Meaning dimension. For the A/A group, all items load on their intended factor with appropriate magnitudes. Second, congruence coefficients (CCs; Gorsuch 1983) were calculated to determine the extent to which the two sets of loadings are identical. CCs provide values between zero and one, with values of 0.90 or above indicating that the two sets of loadings are the same. The last column of Table 2 provides CCs for each NMI item. The loadings of each item across all three factors are compared in both groups. As can be seen, the CCs for 19 of the 22 items indicate that they load similarly across the two groups. The bottom row provides CCs for each factor, determining whether the pattern loadings in each group for each factor are similar, which was found here. Lastly, the last CC (0.96) in bottom row provides an overall measure of agreement across both items and factors, essentially testing whether the overall matrices of loadings are the same, which these findings indicate. Thus, despite whatever mean level differences in scores observed between the two groups, both groups generate identical factor structures. 


\subsection{Predictive Analyses}

The personality scales and the three NMI scales were correlated with the clinical outcome scales and the results are presented in Table 3. As expected, the personality dimension of ES was significantly correlated with the outcome scales in both groups and to similar magnitudes ( $M$ correlation for A/A group $=0.576 ; M$ correlation for BEL group $=0.552$ ). Neuroticism is a broad-based predictor of affective lability. Of interest are the correlations between the two groups on Worthiness. All the clinical scales correlate significantly with $\mathrm{W}$ and are of similar magnitude across the two groups ( $M$ correlation for $\mathrm{A} / \mathrm{A}$ group $=0.534 ; M$ correlation for BEL group $=0.559$ ). Again, despite mean level differences on the NMI between the two groups, scores for both groups on W correlate, with similar magnitude, with the clinical scales.

Table 3. Correlations Between Personality, Worthiness, and the Depression, Anxiety, and Stress Scale (DASS) and Personality Inventory for DSM-5 (PID-5) Scales Separately by Faith Status.

\begin{tabular}{|c|c|c|c|c|c|c|c|c|}
\hline \multirow{2}{*}{ Outcomes } & \multicolumn{8}{|c|}{ Predictors } \\
\hline & $\mathbf{W}$ & I & $\mathbf{M}$ & ES & $\mathbf{E}$ & $\mathbf{O}$ & A & C \\
\hline \multicolumn{9}{|l|}{ A/As $(n=491)$} \\
\hline PID-NA & $-0.49 * * *$ & 0.04 & 0.01 & $-0.79^{* * *}$ & $-0.21^{* * *}$ & $-0.16^{* * *}$ & $-0.20^{* * *}$ & $-0.38^{* * *}$ \\
\hline PID-Detach & $-0.68^{* * *}$ & -0.04 & 0.03 & $-0.48^{* * *}$ & $-0.47^{* * *}$ & $-0.28 * * *$ & $-0.50 * * *$ & $-0.32^{* * *}$ \\
\hline PID-Antag & $-0.31^{* * *}$ & 0.05 & $0.16^{* * *}$ & $-0.31^{* * *}$ & 0.07 & $-0.13^{* *}$ & $-0.45^{* * *}$ & $-0.22 * * *$ \\
\hline PID-Disinhib & $-0.42 * * *$ & $0.10 *$ & $0.17^{* * *}$ & $-0.37^{* * *}$ & -0.04 & $-0.21^{* * *}$ & $-0.28^{* * *}$ & $-0.56^{* * *}$ \\
\hline PID-Psychotic & $-0.48^{* * *}$ & $0.10 *$ & $0.17^{* * *}$ & $-0.50^{* * *}$ & $-0.12^{* *}$ & $-0.16^{* * *}$ & $-0.32^{* * *}$ & $-0.43^{* * *}$ \\
\hline DASS-Stress & $-0.56^{* * *}$ & 0.01 & 0.07 & $-0.74^{* * *}$ & $-0.16^{* * *}$ & $-0.15^{* * *}$ & $-0.24^{* * *}$ & $-0.40^{* * *}$ \\
\hline DASS-Anxiety & $-0.54 * * *$ & 0.06 & $0.12 * *$ & $-0.59 * * *$ & $-0.15^{* * *}$ & $-0.23 * * *$ & $-0.23 * * *$ & $-0.35 * * *$ \\
\hline DASS-Depression & $-0.68 * * *$ & -0.07 & 0.01 & $-0.68^{* * *}$ & $-0.26^{* * *}$ & $-0.17^{* * *}$ & $-0.27^{* * *}$ & $-0.40^{* * *}$ \\
\hline DASS-Total Score & $-0.65^{* * *}$ & -0.01 & 0.07 & $-0.73^{* * *}$ & $-0.21 * * *$ & $-0.20^{* * *}$ & $-0.27 * * *$ & $-0.42 * * *$ \\
\hline \multicolumn{9}{|l|}{ Believers $(n=908)$} \\
\hline PID-NA & $-0.52 * * *$ & $-0.12^{* * *}$ & $-0.15^{* * *}$ & $-0.77^{* * *}$ & $-0.24^{* * *}$ & $-0.19^{* * *}$ & $-0.24^{* * *}$ & $-0.40^{* * *}$ \\
\hline PID-Detach & $-0.65^{* * *}$ & $-0.22 * * *$ & $-0.17^{* * *}$ & $-0.50^{* * *}$ & $-0.39 * * *$ & $-0.24^{* * *}$ & $-0.51^{* * *}$ & $-0.38^{* * *}$ \\
\hline PID-Antag & $-0.45^{* * *}$ & $-0.32 * * *$ & $-0.22^{* * *}$ & $-0.34^{* * *}$ & 0.04 & $-0.19 * * *$ & $-0.54^{* * *}$ & $-0.43^{* * *}$ \\
\hline PID-Disinhib & $-0.48 * * *$ & $-0.25 * * *$ & $-0.19 * * *$ & $-0.41 * * *$ & -0.02 & $-0.19^{* * *}$ & $-0.43^{* * *}$ & $-0.58 * * *$ \\
\hline PID-Psychotic & $-0.53 * * *$ & $-0.17^{* * *}$ & $-0.15^{* * *}$ & $-0.50^{* * *}$ & $-0.16^{* * *}$ & $-0.07 *$ & $-0.42^{* * *}$ & $-0.46^{* * *}$ \\
\hline DASS-Stress & $-0.56^{* * *}$ & $-0.12 * * *$ & $-0.15^{* * *}$ & $-0.68^{* * *}$ & $-0.18 * * *$ & $-0.14^{* * *}$ & $-0.29 * * *$ & $-0.40^{* * *}$ \\
\hline DASS-Anxiety & $-0.52 * * *$ & $-0.18 * * *$ & $-0.16^{* * *}$ & $-0.51 * * *$ & $-0.12 * * *$ & $-0.16^{* * *}$ & $-0.30^{* * *}$ & $-0.38 * * *$ \\
\hline DASS-Depression & $-0.69 * * *$ & $-0.21^{* * *}$ & $-0.18^{* * *}$ & $-0.61^{* * *}$ & $-0.24^{* * *}$ & $-0.19 * * *$ & $-0.34^{* * *}$ & $-0.38^{* * *}$ \\
\hline DASS-Total Score & $-0.65^{* * *}$ & $-0.19 * * *$ & $-0.18 * * *$ & $-0.65^{* * *}$ & $-0.19^{* * *}$ & $-0.18^{* * *}$ & $-0.34^{* * *}$ & $-0.42^{* * *}$ \\
\hline
\end{tabular}

${ }^{*} p<0.05 .{ }^{* *} p<0.01 .{ }^{* * *} p<0.001$, two-tailed. PID-NA = PID-5 Negative Affect; PID-Detach = PID-5 Detachment; PID-Antag = PID-5 Antagonism; PID-Disinhib = PID-5 Disinhibition; PID-Psychotic = PID-5 Psychoticism; DASS = Depression, Anxiety, and Stress Scale; A/A = Atheists/Agnostics; $\mathrm{W}=$ Worthiness; I = Infinitude; $\mathrm{M}=$ meaning.

The above findings demonstrates that the numinous is indeed related to these psychological outcomes. However, in order to demonstrate that the numinous represents an independent and unique predictor or distress, an important question need to be answered, "To what extent do these associations with Worthiness represent unique effects or are merely artifacts of the NMI scales' overlap with the content of the FFM scales?" While conceptualized to be independent dimensions, to the extent that the NMI scales have content that overlaps with Emotional Stability on the IPIP-50, then such associations reflect this contaminated content. In order to answer this question, a series of nine hierarchical regression analyses were conducted for each group, systematically using one of the clinical scales as the outcome (i.e., four using the DASS and five using the PIQ-5). On step 1 of the analysis, the five personality dimensions were entered simultaneously. On step 2, the three NMI scales were then entered using a forward entry technique. A partial $F$-test was conducted to determine whether any of the NMI scales had significant, incremental predictive validity over the FFM domain scores. Further, an inspection of the beta weights will allow for a determination of the relative unique predictive contributions of these scales. The results are for the DASS are presented in Table 4. 
Table 4. Incremental Validity of the NMI Scales over the Five-Factor Model (FFM) Domains in Predicting Emotional Distress on the DASS for Atheist/Agnostics and Other Faith Traditions.

\begin{tabular}{|c|c|c|c|c|}
\hline Measure & Overall $R^{2}$ & FFM R ${ }^{2}$ & NMI $\Delta R^{2}$ & Predictors (Beta) \\
\hline \multicolumn{5}{|c|}{ Atheists/Agnostics $(n=491)$} \\
\hline Stress & 0.59 & $0.57^{* * *}$ & $0.02^{* * *}$ & ES (-0.62) E (0.09) W (-0.22) \\
\hline Anxiety & 0.42 & $0.37^{* * *}$ & $0.05^{* * *}$ & ES (-0.42) W (-0.28) M (0.08) \\
\hline Depression & 0.60 & $0.49 * * *$ & $0.12 * * *$ & ES $(-0.41) \mathrm{O}(0.11) \mathrm{W}(-0.47) \mathrm{I}(-0.07)$ \\
\hline Overall DASS & 0.62 & $0.56^{* * *}$ & $0.07^{* * *}$ & $\mathrm{ES}(-0.52) \mathrm{W}(-0.36)$ \\
\hline \multicolumn{5}{|l|}{ Believers $(n=907)$} \\
\hline Stress & 0.53 & $0.49^{* * *}$ & $0.04^{* * *}$ & $\mathrm{ES}(-0.51) \mathrm{O}(0.05) \mathrm{C}^{-}(-0.08) \mathrm{W}(-0.27)$ \\
\hline Anxiety & 0.36 & $0.31^{* * *}$ & $0.05^{* * *}$ & $\begin{array}{l}\text { ES }(-0.31) \text { E }(0.08) \text { A }(-0.08) \text { C }(-0.12) \\
W(-0.30)\end{array}$ \\
\hline Depression & 0.56 & $0.42 * * *$ & $0.14^{* * *}$ & $\mathrm{ES}(-0.32) \mathrm{W}(-0.49)$ \\
\hline Overall DASS & 0.56 & $0.48^{* * *}$ & $0.09^{* * *}$ & $\mathrm{ES}(-0.42) \mathrm{A}(-0.06) \mathrm{C}(-0.09) \mathrm{W}(-0.39)$ \\
\hline
\end{tabular}

DASS = Depression, Anxiety, Stress Scale; ES = Emotional Stability; $\mathrm{E}=$ Extraversion; $\mathrm{O}=$ Openness; $\mathrm{A}=$ Agreeableness; $\mathrm{C}=$ Conscientiousness; $\mathrm{W}=$ Worthiness; $\mathrm{I}=$ Infinitude; $\mathrm{M}=$ Meaning. ${ }^{* * *} p<0.001$.

As can be seen, the personality dimension of ES was a consistent significant predictor of all DASS scales in both groups. The findings are consistent with the correlational data. The obtained $\mathrm{R}^{2}$ values indicate that the personality scales explain a large amount of variance in the DASS scales. However, it is also important to note that the NMI scales also contributed a significant amount of additional explanatory variance in each of the DASS scales (from $2 \%$ to $14 \%$ additional variance, a quite substantial amount, Hunsley and Meyer 2003). Two points of interest in Table 4. First, Worthiness was a consistent predictor for each DASS scale, the other NMI scales had less relevance. Surprisingly, additional NMI scales were found to predict only in the A/A group. Apparently, Infinitude and Meaning provide additional predictive power for understanding emotional dysphoria only for atheists and agnostics.

Second, the magnitude of incremental predictiveness found for the NMI is similar between the two groups (A/A group mean $\Delta \mathrm{R}^{2}=0.07$; BEL group mean $\Delta \mathrm{R}^{2}=0.08$ ). The NMI scales have comparable relevance for understanding emotional distress for believers and non-believers.

Table 5 presents the regression results with the PID-5. These scales capture dysfunctional personality dimensions related to the FFM and represent a more personologically diverse set of constructs than the DASS. There are three points of interest. First, Emotional Stability was a consistent predictor of all PID-5 scales, although it is not always the largest predictor (e.g., $\mathrm{C}$ was most relevant for Inhibition, A was most relevant for Antagonism, E and A were strongest for Detachment). Worthiness was also a consistent significant predictor for all analyses except for Antagonism in the A/A group, where $\mathrm{M}$ emerged as significant. Interestingly, Worthiness was the strongest predictor for Detachment in both groups, being twice as large as any of the FFM domains.

Second, as found with the DASS, the NMI's unique predictive contribution was comparable in strength across the two groups, again underscoring the equal relevance of these numinous constructs for both believers and non-believers. The content of the NMI contains information that is relevant and appropriate for all people; responses do not require any specific theological orientation or metaphysical world view for scores to be meaningful.

\subsection{SEM Analyses}

While Worthiness (W) is a unique, significant predictor of both emotional and characterological impairment, it is not clear why this association exists. Is it because $\mathrm{W}$ has a causal impact on the experience of impairment or because $\mathrm{W}$ represents another facet of negative affect that is a consequence of levels of ES? In order to determine the answer to this ultimate question of utility, a series of causal models were examined.

Figure 1 presents three different models that postulate varying causal roles for $\mathrm{W}$ consistent with Piedmont and Wilkins (2020) ontological model of the numinous. Model 1 positions W as an independent predictor of distress from the FFM. Here, $\mathrm{W}$ is its own causal motivation that works 
additively with personality to impact levels of emotional dysphoria. The remaining models present $\mathrm{W}$ as an outcome of personality (Model 2) or an outcome of both personality and the experience of impairment (Model 3). Further, these models are evaluated separately for the two belief groups to determine if W's role may vary. Would $\mathrm{W}$ be a causal agent only for believers? Would it have a different psychological role to play with non-believers? Would its role vary across the type of impairment being evaluated: Affective vs. characterological? Using the SEM software Linear Structural Relations (LISREL version 8.73), these different models were examined in the current data set and the results are presented in Table 6.

Table 5. Incremental Validity of the NMI Scales over the FFM Domains in Predicting Characterological Dysfunction on the PID-5 for Atheist/Agnostics and Other Faith Traditions.

\begin{tabular}{|c|c|c|c|c|}
\hline Measure & Overall $\mathbf{R}^{2}$ & FFM R $^{2}$ & NMI $\Delta \mathbf{R}^{2}$ & Predictors (Betas) \\
\hline \multirow[t]{2}{*}{ Psychotic } & 0.38 & $0.34 * * *$ & $0.04 * * *$ & $\mathrm{ES}(-0.28) \mathrm{O}(0.08) \mathrm{A}(-0.18) \mathrm{C}(-0.20) \mathrm{W}(-0.20) \mathrm{M}(0.11) \mathrm{I}(0.08)$ \\
\hline & & & & $\mathrm{ES}(-0.10) \mathrm{E}(0.10) \mathrm{A}(-0.13) \mathrm{C}(-0.42)$ \\
\hline Inhibition & & & & $\mathrm{ES}(-0.26) \mathrm{E}(0.26) \mathrm{A}(-0.48) \mathrm{M}(0.10)$ \\
\hline Antagonism & 0.33 & $0.32 * * *$ & $0.01 *$ & $\mathrm{ES}(-0.11) \mathrm{E}(-0.22) \mathrm{O}(0.10) \mathrm{A}(-0.24)$ \\
\hline Detachment & 0.57 & $0.46^{* * *}$ & $0.11 * * *$ & $\mathrm{~W}(-0.46)$ \\
\hline Negative Affect & \\
\hline & 0.45 & $0.41 * * *$ & $0.04 * * *$ & $\mathrm{ES}(-0.25) \mathrm{O}(0.22) \mathrm{A}(-0.24) \mathrm{C}(-0.22)$ \\
\hline & & & & $\mathrm{W}(-0.27)$ \\
\hline \multirow[t]{2}{*}{ Inhibition } & 0.46 & $0.43^{* * *}$ & $0.03 * * *$ & $\mathrm{ES}(-0.13) \mathrm{E}(0.15) \mathrm{O}(0.07) \mathrm{A}(-0.20)$ \\
\hline & & & & $\mathrm{C}(-0.39) \mathrm{W}(-0.23)$ \\
\hline Antagonism & 0.44 & $0.42 * * *$ & $0.03^{* * *}$ & $\mathrm{ES}(-0.14) \mathrm{E}(0.23) \mathrm{O}(0.07) \mathrm{A}(-0.43)$ \\
\hline
\end{tabular}

PID-5 = Personality Inventory for the DSM-5; ES = Emotional Stability; E = Extraversion; O = Openness; A = Agreeableness; $\mathrm{C}=$ Conscientiousness; $\mathrm{W}=$ Worthiness; $\mathrm{I}=$ Infinitude; $\mathrm{M}=$ Meaning. ${ }^{*} p<0.05 .{ }^{* * *} p<0.001$.

Table 6. Results of SEM Analyses for Three Causal Models Comparing Atheists/Agnostics and Believers on Measures of Emotional and Characterological Impairment.

\begin{tabular}{|c|c|c|c|c|c|c|c|}
\hline Outcome & Groups & $\mathrm{X}^{2}$ & $d f$ & $\mathrm{X}^{2} / N$ & RMSEA & SRMR & AIC \\
\hline \multirow{8}{*}{$D A S S$} & $A / A s(n=491)$ & & & & & & \\
\hline & Model 1 & 27.19 & 6 & 4.53 & 0.085 & 0.019 & 105.19 \\
\hline & Model 2 & 78.47 & 10 & 7.85 & 0.12 & 0.025 & 148.47 \\
\hline & Model 3 & 43.95 & 9 & 4.88 & 0.089 & 0.027 & 115.95 \\
\hline & Believers $(n=907)$ & & & & & & \\
\hline & Model 1 & 34.28 & 6 & 5.7 & 0.072 & 0.015 & 112.28 \\
\hline & Model 2 & 56.22 & 8 & 7.1 & 0.082 & 0.024 & 130.22 \\
\hline & Model 3 & 125.9 & 10 & 12.59 & 0.11 & 0.024 & 195.9 \\
\hline \multirow{8}{*}{ PID-5 } & $A / A s(n=491)$ & & & & & & \\
\hline & Model 1 & 28.07 & 8 & 3.51 & 0.072 & 0.023 & 144.07 \\
\hline & Model 2 & 62.5 & 9 & 6.94 & 0.11 & 0.04 & 176.5 \\
\hline & Model 3 & 50.86 & 13 & 3.91 & 0.077 & 0.033 & 156.86 \\
\hline & Believers $(n=907)$ & & & & & & \\
\hline & Model 1 & 19.89 & 9 & 2.21 & 0.037 & 0.013 & 133.89 \\
\hline & Model 2 & 42.43 & 11 & 3.85 & 0.056 & 0.016 & 152.43 \\
\hline & Model 3 & 55.03 & 15 & 3.67 & 0.054 & 0.021 & 157.03 \\
\hline
\end{tabular}

DASS = Depression, Anxiety, and Stress Scale; PID-5 = Personality Inventory for DSM-5; A/A = Atheists and Agnostics; RMSEA = Root Mean Square Error of Approximation; SRMR = Standardized Root Mean Residual; AIC = Akaike Information Criterion. 


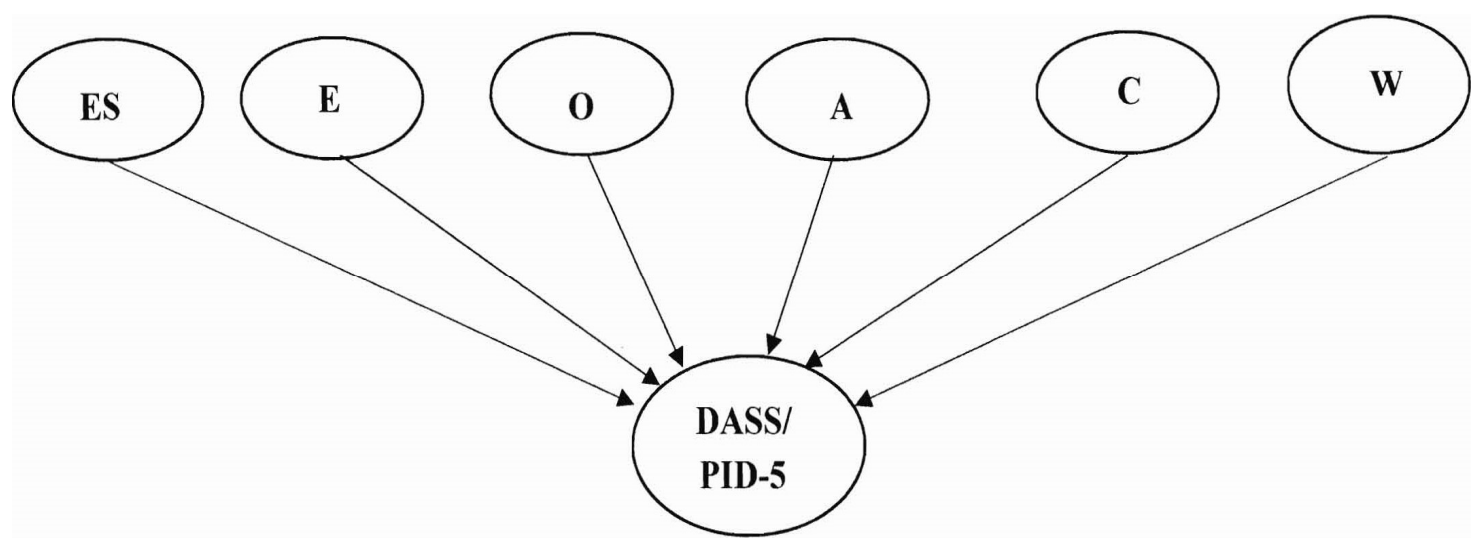

Model 1 : Worthiness as Unique Predictor of DASS and PID-5

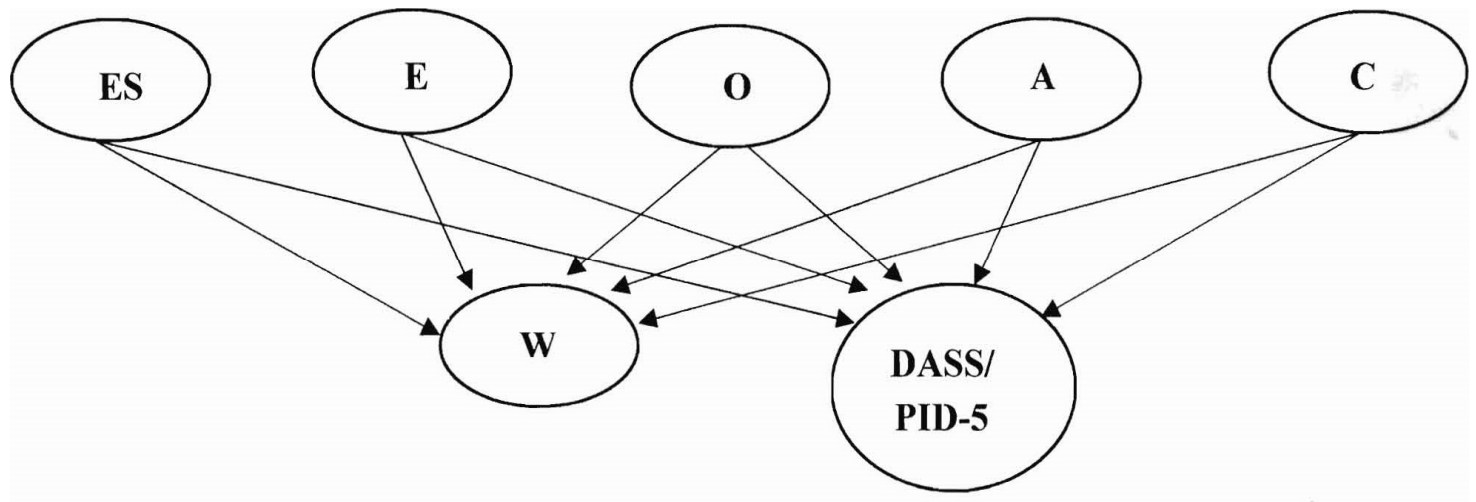

Model 2: W and DASS/PID-5 as Outputs of Personality

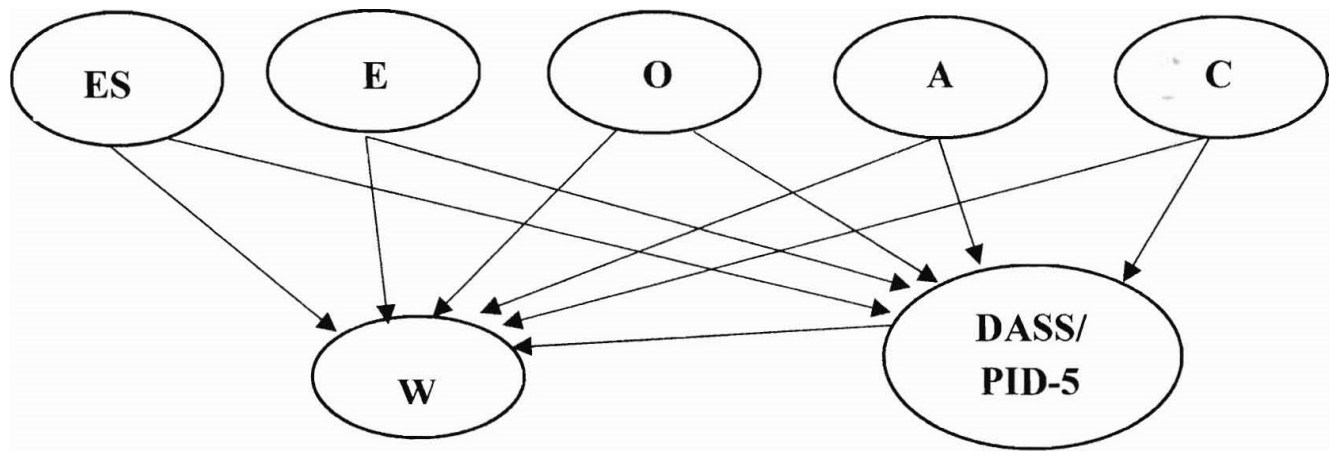

Model 3: W as an Output of Personality and DASS/PID-5

Figure 1. Proposed Structural Models Linking Worthiness, Personality, and Psychological Distress. DASS = Depression, Anxiety, and Stress Scale; PID-5 = Personality Inventory for DSM-5; W Worthiness; $\mathrm{ES}=$ Emotional Stability; $\mathrm{E}=$ Extraversion; $\mathrm{O}=$ Openness; $\mathrm{A}=$ Agreeableness $; \mathrm{C}=$ Conscientiousness.

The first observation is that the pattern of results were similar for both belief groups. Second, a similar causal pattern was found for both the emotional and characterological scales. The experience of emotional dysphoria, whether temperament-based or situationally-induced, was similarly impacted by numinous motivations. Specifically, low scores on $W$ represented a core sensitivity to the experience of emotional difficulties. Third, Model 1 which presented $W$ as a unique causal predictor of distress, was the best fitting model across all the fit statistics examined using criteria proposed by $\mathrm{Hu}$ and Bentler (1999) as well as Kline (2016; i.e., $\chi 2 / \mathrm{N}<5$; RMSEA and SRMR < 0.08). Of particular interest 
is the Akaike Information Criterion (AIC). This index is used when non-nested models are being compared. The AIC examines the parsimony and level of fit for each model in terms that can be directly compared. The model with the lowest AIC is seen as the best fitting model. In Table 6, the AIC analysis indicated that Model 1 fit best in all four analyses. These results supported viewing $\mathrm{W}$ as a motivational construct which can potentially impact the psychological equilibrium of individuals independently of any personality dispositions.

The standardized weights (lambdas) for the six contributing factors as portrayed in Model 1 are presented in Table 7. There are two points of interest. First, the NMI W scale made a significant, unique contribution to the experience of affective and characterological dysregulation. Understood as a unique causal agent, $\mathrm{W}$ had a moderately sized impact on the clinical outcome variables. Its contribution compared favorably to the effect for ES. Second, there was an interesting differential pattern of predictiveness in these data. When considering the DASS, W played an important, though smaller, role than ES. For the A/A group, W's contribution was $69 \%$ that of ES (i.e., $-0.38 /-0.55$ ), while for the BEL group, it was $95 \%$ (i.e., $-0.36 /-0.38$ ). However, when considering the personality disorder outcome, $\mathrm{W}$ was a stronger predictor than personality, being $1 \frac{1}{2}$ times stronger in the A/A group (i.e., $-0.49 /-0.32)$ to almost two and a half times stronger in the BEL group $(-0.39 /-0.16)$. These findings support viewing the numinous as a core, organizing praxis to our psychological systems: $\mathrm{W}$ was a better predictor of characterological style than it was of context dependent emotional experiences.

Table 7. Standardized Loadings (Lambdas) for the Numinous and Personality Constructs on the DASS and PID-5 from Model 1.

\begin{tabular}{lcccccc}
\hline \multirow{2}{*}{ OUTCOME } & \multicolumn{7}{c}{ Standardized Path Coefficients (Lambdas) } \\
\cline { 2 - 7 } & W & ES & E & O & A & C \\
\hline A/A & & & & & & \\
DASS & -0.38 & -0.55 & 0.03 & -0.09 & -0.03 & -0.07 \\
PID-5 & -0.49 & -0.32 & 0.24 & 0.06 & -0.27 & -0.21 \\
BEL & & & & & & \\
DASS & -0.36 & -0.38 & 0.01 & -0.05 & -0.07 & -0.07 \\
PID-5 & -0.39 & -0.16 & 0.03 & 0.08 & -0.26 & -0.25 \\
\hline
\end{tabular}

$\mathrm{A} / \mathrm{A}=$ Atheists/Agnostics; BEL = Believers; DASS = Depression, Anxiety, and Stress Scale; PID-5 = Personality Inventory for the DSM-5; $\mathrm{W}=$ Worthiness; $\mathrm{ES}=$ Emotional Stability; $\mathrm{E}=$ Extraversion; $\mathrm{O}=$ Openness; $\mathrm{A}=$ Agreeableness; $\mathrm{C}=$ Conscientiousness for understanding emotional and characterological dysregulation.

\section{Discussion}

The results of this study provide strong support for the basic assumptions of Piedmont's (Piedmont 2015; Piedmont and Wilkins 2020) ontological model of numinous motivation. First, this study replicated previous research by Fox and Piedmont (2020) that demonstrated the unique predictive role of religious crisis on emotional dysphoria. Using a different sample and measure of religious crisis, the unique role of the numinous on ratings of depression, anxiety, and stress were replicated here. Further, the current study also replicated findings by Piedmont et al. (2007) that demonstrated the unique causal role of the numinous for understanding characterological impairment. When properly developed measures of the numinous are used (i.e., scales which have demonstrated uniqueness from and incremental validity over measures of the Five-Factor Model (FFM) of personality; see Piedmont and Wilkins 2020), numinous motivations are being shown increasingly to represent important psychological aspects of the individual that have significant, substantive implications for understanding emotional and characterological dysregulation.

\subsection{The Universal Relevance of the Numinous}

The current study further supports Piedmont's ontological model by directly examining a key hypothesis: The universal nature of the numinous. The numinous appears to represent a core, species-defining aspect of human psychological functioning whose effects can be found in all people, 
irrespective of any religious affiliation or theological preference. Despite representing a sample that is representative of the secularization hypothesis (Atheists and Agnostics), the data in this study can be taken as counter evidence to the claim that when religion ceases to be a relevant construct of personal identity that numinous issues dissipate as a matter of course. On the contrary, the current findings clearly demonstrated the utility of the numinous for understanding both emotional dysphoria and characterological impairment for both believers and atheists/agnostics. As shown in this paper, both believers and non-believers understood the nature of numinous motivations in similar ways and scores on the NMI were shown to predict their clinical outcomes. Of importance, the magnitude of prediction for the NMI was comparable for both groups, underscoring the equal relevance of numinous constructs across different faith orientations.

It is also important note that while the NMI scales added significant incremental predictive validity over the FFM, in one instance the NMI was a stronger predictor than the FFM. Table 5 documented that Worthiness (W) was a stronger predictor of Detachment than ES, for both groups. Given the underlying relational nature of content on the $\mathrm{W}$ scale, this finding provides additional construct evidence for this scale. It also underscores the relevance of numinous motivations for expanding our understanding of characterological defects. In fact, the strong predictiveness of $W$ on Detachment suggests that any clinical understanding of this construct would be woefully inadequate without a consideration of the numinous.

Table 5 also provided additional support for our contention that the dimension of $\mathrm{W}$ represents aspects of maladaptation that are independent of the personality domain of neuroticism (low ES). Numinous motivations represented a distinct aspect of psychological functioning not contained by established personality models, like the FFM. The findings observed with the Negative Affect scale provided additional support for this perspective. While Table 3 showed that ES correlated over 0.75 with the PID-NA scale in both groups, it is interesting to note that in Table 5 no NMI scale, particularly W, added much, if any, incremental predictiveness to this clinical outcome. For the A/A group, the NMI is completely independent and in the BEL group it added only a very small amount of additional variance (i.e., $1 \%$ ). These findings support the hypothesis that the numinous and emotional dysphoria are separate constructs, with different psychological dynamics. That both predict common clinical outcomes demonstrates the need to broaden current models of psychopathology to include the numinous.

It is interesting to note in Table 7 the pattern of predictiveness across the two outcome domains. While scores on the $\mathrm{W}$ scale evidenced similar levels of predictiveness for the two study groups, $\mathrm{W}$ was a stronger predictor of characterological impairment than emotional dysphoria, for both groups, while the reverse was true on the DASS. Clearly, W correlated more strongly with characterological outcomes than context dependent emotional states. This finding suggests that $\mathrm{W}$ does represent an intrinsic, stable, personological quantity. Taken as a whole, these findings should provide reassurance to researchers and clinicians that aspects of the numinous reflect important qualities of the mental life of all individuals. Further, an assessment of these qualities will provide non-redundant insights into the psychological status of clients that will have significant implications for treatment.

\subsection{Clinical Next Steps}

Because numinous constructs bring an entirely new dimension of analysis for clinical work, some overview of how to apply the current findings in treatment seems warranted. Collecting information regarding a client's numinous status at the beginning of treatment, along with measures of personality and psychological functioning, is ideal for gathering a comprehensive understanding of the psycho-social strengths and weaknesses of the client. This assessment could be done in one of two ways (or both). One could employ a validated measure of the numinous, like the NMI, or information could be gathered during the clinical intake phase. Usually, when clients first appear for treatment they are screened across a number of relevant clinical dimensions, such as history of treatment, type of presenting problem and its duration, cognitive functioning, and psychosocial status. Unfortunately, 
most screenings do not include much of an assessment of numinous functioning. While it may be more typical to query whether someone is a believer or not, or whether they consider themselves religious or not, little is done to move deeper into this domain. The Comprehensive Psycho-Spiritual Clinical Interview (CPSCI; Piedmont and Wilkins 2020) was designed to offer an initial screening that is all inclusive.

This interview format was designed to be efficient and useful for clinical work by promoting a multidimensional understanding of the client. It contains four areas of examination: The Presentation, how the client appears physically and cognitively; the Problem, which examines the current presenting problem and psychiatric history; the Person, which assesses a number of personologically relevant dimensions; and the Predicament, which provides an assessment of the numinous dimensions of the client. One particularly useful feature of the CPSCI is that it includes normed scales that allow for a more inferential understanding of the client. For example, on the Predicament section, there are a number of items that capture aspects of the numinous, like the NMI dimensions of Infinitude (I), Meaning (M), and Worthiness (W). Therapists can check those elements for each of the dimensions that are descriptive of the client. Aside from being individually reflective of numinous issues, aggregating ratings across these items will create a scale score, and the normative data for each of these measures allows for a deeper understanding of where clients stand on these dimensions (see Piedmont and Wilkins 2020).

Treatment approaches to effectively resolving numinous concerns are less established. However, the available research may suggest that numinous concerns are less powerfully effected through secular psychotherapy. In a meta-analysis by Captari et al. (2018), they noted when treatment approaches explicitly incorporate clients' religious and spiritual perspectives, they have been found to be equally efficacious on psychological outcomes compared to secular psychotherapy, and superior on numinous related outcomes. It is possible that this dynamic is due in part to the fact that the world's religions focus so intently on the numinous. Their sheer staying power, which spans across thousands of years, can partly be attributed to the fact that they offer humanity compelling means of addressing problems related to Infinitude, Worthiness, and Meaning. While they are diverse in how they do this, they hold in common highly developed sets of philosophical insights into the nature of what it means to be human, elaborate and cohesive meta-narratives that gives meaning to the human journey, and tried and true practices for exercising numinous motivations to their fullest potential across the lifespan (Grassie 2010). The next question for researchers and clinicians to explore, then, is how the insights of the world's religions, and their apparently well tested methods of addressing numinous concerns through their particular means, can be generalized to non-religious patients.

Treatment samples studied so far have not been inclusive of these groups when examining the numinous and they have not been well tested on measurement models that are universal. As more people in the West embrace secularization, there would appear to be a gap between numinous motivations, when they are frustrated or left unmet, and effective means of adequately addressing them in ways conducive to atheists' and agnostics' frameworks of meaning. It is possible that the treasures of the world religions may yet still be of relevance to those who no longer belong to them. How they may be applied to the numinous concerns of atheist and agnostics in psychotherapy represents the cutting edge of the PRS.

\subsection{Measurement Considerations}

While numinous motivations represent universal aspects of the mental lives of people, most measures of R/S phenomena are quite religiously focused (see Hill and Hood 1999). These scales frequently employ very specific religious language that reflects particular theologies and denominational approaches. While such items may be of maximum relevance to adherents of these different denominations, they are much less useful when given to those who do not share such sentiments. Thus, it is not unexpected that atheists and agnostics have played a very limited role in research in this area. After all, if one does not believe in any transcendent realities, then measures that assess such 
qualities would be of little or no relevance. Further, non-believers may be put off by such instruments because the item content is irrelevant to them, thus making their scores unreliable.

In assessing numinous constructs, it is important that items reflect non-religious content, ensuring its broad relevance. The NMI is considered a second generation measure (Piedmont, in press) because it capitalizes on both a developed ontological model and over 25 years of research using the Assessment of Spirituality and Religious Sentiments (ASPIRES) scale (Piedmont 2020). While the ASPIRES worked very well and was found useful with respondents from all faith traditions, including atheists and agnostics (Toscano et al. 2017), there was always a concern that even in a scale that attempted to be non-religious, religious material was present (e.g., references to God, higher power/being). This would create issues for respondents who were either unfamiliar with the religious terminology or found it irrelevant. Toscano et al. (2017) demonstrated that the ASPIRES was a significant predictor of purpose in life and affect for both believers and atheists. However, the magnitude of prediction was substantially less in the atheist group.

The NMI was designed to remove much of this theistic-type language and replace it with secular, existential verbiage, thereby preventing potential religious-oriented demand characteristics in the items from obstructing genuine responses to the underlying latent numinous constructs (e.g., I, W, and $\mathrm{M}$ ). The results of this study demonstrated the success of this new instrument. As these findings showed, the predictive power of the NMI was almost identical in the two groups; scores from atheists and agnostics on Worthiness were equally reliable and equally predictive of all the clinical outcomes. Researchers wishing to plumb the psychological depths of $R / S$ constructs with non-believers or with adherents of faith communities that do not ascribe to a belief in a transcendent being (e.g., Buddhists, Janists, Shintoist, etc.) will need to redact their scales of such content in favor of broader concepts.

\subsection{Limitations}

Three particular issues need consideration. First, while the sampling method was able to access a national sample of adults, all the data examined in this study was self-report based. While a useful source of information, reliance on a single information source raises concerns over common method bias. Self-report scores will always correlate with each other to some degree because it is the same person answering each scale. Unique subject characteristics in response style will create spurious associations across instruments. It is unclear to what extent this occurred in the current study. Future research needs to include other data sources (e.g., observer ratings) as a check on the accuracy of these findings. Further, observer data has its own predictive validity and provides its own unique insights into the target of the rating. While most $\mathrm{R} / \mathrm{S}$ scales do not have validated rating versions, both the ASPIRES and NMI do, although they were not used in this study.

A second issue concerns the SEM findings. It must be remembered, that SEM analyses do not demonstrate causality in the data, only an experiment can do that. What SEM does, is examine the viability of the putative causal pathways that are specified in the tested model. Showing that the data fit a particular model only indicates that the underlying causal assumptions are consistent with the observed data. In working with clinical outcome variables, it is ethically challenging to apply experimental designs, thus SEM becomes a useful technique for approximating the viability of a particular model. Thus, the models tested here await future replications using experimental designs where appropriate. However, that the current findings replicate several, previous studies gives enhanced confidence in the accuracy of the presented model.

Finally, whereas the MTurk worker model did provide a broad sample, including workers from all 50 US states, demographically the participants were overwhelming European-American (75\%) and well educated, most having a college degree of higher (57\%). Whereas the system was useful in obtaining a variety people from different occupations, income levels, and religious affiliations, the results must be interpreted within the racial and educational limits of our sample. Because MTurk is a useful platform for collecting large samples, we recommend that future research of this type make the 
effort to recruit larger samples than ours so that a demographically representative subset of useful size can be culled from the total.

\section{Conclusions}

There is much to be excited about by these data. It is becoming increasingly clear that numinous motivations represent aspects of psychological functioning not contained by traditional models of personality and psychopathology. When speaking about humanity's higher nature, Maslow (1971) noted that there could be motivational pathologies that emerge when self-actualized individuals were deprived of key elements of their ultimate self, such as feelings of despair and feeling unneeded. These negative feelings may be at the heart of psychological problems that are not yet studied scientifically. With the numinous emerging as a conceptually clear, empirically robust construct, an opportunity for expanding our psychological knowledge is at hand. Disorders that currently remain refractive to contemporary treatment approaches (e.g., moral injury, body image dysphoria, suicide) may become more tractable when viewed from a numinous perspective. The numinous is a universal quality of value in learning about every client. As discussed in this paper, there are technologies that are available for clinicians to use in their practice to explore for themselves the potential interpretive value of these constructs for promoting healing, growth, and resilience in their clients.

Author Contributions: Conceptualization, R.L.P., J.F. and M.E.T.; Formal analysis, R.L.P. and M.E.T.; Funding acquisition, R.L.P.; Investigation, R.L.P.; Methodology, R.L.P.; Project administration, R.L.P. and M.E.T.; Writing-original draft, R.L.P.; Writing—review \& editing, R.L.P. and J.F. All authors have read and agreed to the published version of the manuscript.

Funding: This research received a faculty development grant to Piedmont from the Department of Pastoral Counseling at Loyola University Maryland.

Conflicts of Interest: Ralph L. Piedmont receives royalties from the sale of the Numinous Motivation Inventory.

\section{References}

Alter, Margaret G. 1989. An empirical study of Christian religious maturity: Its implications for parish ministry. Pastoral Psychology 37: 153-60. [CrossRef]

American Psychiatric Association. 2013. Diagnostic and Statistical Manual of Mental Disorders, 5th ed. Arlington: American Psychiatric Association.

Ano, Gene G., and Erin B. Vasconcelles. 2005. Religious coping and psychological adjustment to stress: A meta-analysis. Journal of Clinical Psychology 61: 461-80. [CrossRef] [PubMed]

Brown, Timothy A., Bruce F. Chorpita, William Korotitscw, and David H. Barlow. 1997. Psychometric properties of the Depression Anxiety Stress Scales (DASS) in clinical samples. Behaviour Research and Therapy 35: 79-89. [CrossRef]

Buss, David M. 2002. Sex, marriage, and religion: What adaptive problems do religious phenomena solve? Psychological Inquiry 13: 201-3.

Captari, Laura E., Joshua N. Hook, William Hoyt, Don E. Davis, Stacey E. McElroy-Heltzel, and Everett L. Worthington Jr. 2018. Integrating clients' religion and spirituality within psychotherapy: A comprehensive meta-analysis. Journal of Clinical Psychology 74: 1938-51. [CrossRef] [PubMed]

Chen, Tianzhi P. 2011. Cross-Cultural Psychometric Evaluation of the ASPIRES in Mainland China. Ph.D. dissertation, Loyola University Maryland, Baltimore, MD, USA. Unpublished.

Cohen, Jacob. 1987. Statistical Power Analysis for the Behavioral Sciences, Revised ed. Hillsdale: Lawrence Erlbaum Associates.

Comte-Sponville, André. 2006. The Little Book of Atheist Spirituality. New York: Penguin Books.

Digman, John M. 1990. Personality structure: Emergence of the five-factor model. Annual Review of Psychology 41: 417-40. [CrossRef]

Exline, Julie Juola. 2013. Religious and spiritual struggles. In APA Handbook of Psychology, Religion, and Spirituality. Edited by Kenneth I. Pargament. Washington, DC: American Psychological Association, vol. 1.

Exline, Julie Juola, Ann Marie Yali, and William C. Sanderson. 2000. Guilt, discord and alienation: The role of religious strain in depression and suicidality. Journal of Clinical Psychology 56: 1481-96. [CrossRef] 
Fox, Jesse, and Ralph L. Piedmont. 2020. Religious crisis as an independent causal predictor of psychological distress: Understanding the unique role of the numinous for intrapsychic functioning. Religions 11: 329. [CrossRef]

Funder, David C. 2002. Why study religion? Psychological Inquiry 13: 213-14.

Goldberg, Lewis R. 1992. The development of markers for the Big-Five factor structure. Psychological Assessment 4: 26-42. [CrossRef]

Goldberg, L., J. Johnson, H. Eber, R. Hogan, M. Ashton, C. Clonger, and Association of Research in Personality. 2006. The international personality item pook and the future of public-domain personality measures. Journal of Research in Personality 40: 84-96. [CrossRef]

Gorsuch, Richard L. 1983. Factor Analysis, 2nd ed. Hillsdale: Lawrence Erlbaum Associates.

Grassie, William. 2010. The New Science of Religion: Exploring Spirituality from the Outside in and Bottom up. New York: Palgrave Macmillan.

Hill, Peter C., and Ralph W. Hood Jr. 1999. Measures of Religiosity. Birmingham: Religious Education Press.

Hill, Peter C., Kenneth Pargament II, Ralph W. Hood Jr., Michael E. McCullough, James P. Swyers, David B. Larson, and Brian J. Zinnbauer. 2000. Conceptualizing religion and spirituality: Points of commonality, points of departure. Journal for the Theory of Social Behavior 30: 51-77. [CrossRef]

$\mathrm{Hu}$, Li-tze, and Peter M. Bentler. 1999. Cutoff criteria for fit indices in covariance structure analysis: Conventional criteria versus new alternatives. Structural Equation Modeling 6: 1-55. [CrossRef]

Hunsley, John, and Gregory J. Meyer. 2003. The incremental validity of psychological testing and assessment: Conceptual, methodological, and statistical issues. Psychological Assessment 15: 446-55. [CrossRef]

Joshanloo, Mohsen. 2012. Investigation of the factor structure of spirituality and religiosity in Iranian Shiite university students. International Journal of Psychology 47: 211-21. [CrossRef] [PubMed]

Kline, Rex B. 2016. Principles and Practice of Structural Equation Modeling, 4th ed. New York: Guilford Press.

Koenig, Harold G. 1999. The Healing Power of Faith. New York: Simon and Schuster.

Koenig, Harold G., Michael E. McCullough, and David B. Larson. 2001. Handbook of Religion and Health. New York: Oxford University Press.

Krueger, Robert F., Jaime Derringer, Kristian E. Markon, David Watson, and Andrew E. Skodol. 2012. Initial construction of a maladaptive personality trait model and inventory for DSM-5. Psychological Medicine 42: 1879-90. [CrossRef]

Lawrence, Richard Thomas. 1991. The God Image Inventory: The Development, Validation, and Standardization of a Psychometric Instrument for Research, Pastoral and Clinical use in Measuring the Image of God. Ph.D. dissertation, The Catholic University of America, Washington, DC, USA. Unpublished.

Leach, Mark M., and Tetsuo Sato. 2013. A content analysis of the Psychology of Religion and Spirituality journal: The initial four years. Psychology of Religion and Spirituality 5: 61-68. [CrossRef]

Lovibond, Peter F., and Sydney H. Lovibond. 1995. Manual for the Depression Anxiety Stress Scales, 2nd ed. Sydney: Psychology Foundation of Australia.

Maslow, Abraham Harold. 1971. The Farther Reaches of Human Nature. New York: Viking Press.

McCrae, Robert R. 2010. The place of the FFM in personality psychology. Psychological Inquiry 21: 57-64. [CrossRef]

Mlačić, Boris, and Lewis Goldberg. 2007. An analysis of a cross-cultural personality inventory: The IPIP Big Five factor markers in Croatia. Journal of Personality Assessment 88: 168-77. [CrossRef]

Pargament, Kenneth I. 1999. The psychology of religion and spirituality? Yes and no. International Journal for the Psychology of Religion 9: 3-12. [CrossRef]

Pargament, Kenneth I. 2007. Spiritually Integrated Psychotherapy: Understanding and Addressing the Sacred. New York: Guilford Press.

Pew Research Center. 2015. Religious Landscape Study. Available online: http://www.pewforum.org/religiouslandscape-study/ (accessed on 15 July 2020).

Piedmont, Ralph L. 1998. The Revised NEO Personality Inventory: Clinical and Research Applications. New York: Plenum Press.

Piedmont, Ralph L. 2014. Looking back and finding our way forward: An editorial call to action. Psychology of Religion and Spirituality 6: 265-67. [CrossRef]

Piedmont, Ralph L. 2015. A Psychological Ontology for Understanding Spirituality. Paper presented at the Conference on Values and the Meaning of Life, Poznan, Poland, September 15.

Piedmont, Ralph L. 2017. The Numinous Motivation Inventory: Preliminary Technical Manual. Timonium: Author. 
Piedmont, Ralph L. 2020. Assessment of Spirituality and Religious Sentiments: Technical Manual, 3rd ed. Timonium: Author.

Piedmont, Ralph L., and Mark M. Leach. 2002. Cross-cultural generalizability of the Spiritual Transcendence Scale in India: Spirituality as a universal aspect of human experience. American Behavioral Scientist 45: 1886-99. [CrossRef]

Piedmont, Ralph L., Catherine J. Hassinger, Janelle Rhorer, Martin F. Sherman, Nancy C. Sherman, and Joseph E. G. Williams. 2007. The relations among spirituality and religiosity and Axis II functioning in two college samples. Research in the Social Scientific Study of Religion 18: 53-73.

Piedmont, Ralph L., Joseph W. Ciarrochi, Gabriel S. Dy-Liacco, and Joseph E. G. Williams. 2009. The empirical and conceptual value of the Spiritual Transcendence and Religious Involvement Scales for personality research. Psychology of Religion and Spirituality 1: 162-79. [CrossRef]

Piedmont, Ralph L., and Teresa A. Wilkins. 2020. Understanding the Psychological Soul of Spirituality: A Guidebook for Research and Practice. New York: Routledge.

Piedmont, Ralph L. n.d. The Numinous Motivation Inventory: A second generation measure of spirituality. In The Oxford Handbook of Psychology and Religion, 2nd ed. Edited by Lisa Miller. New York: Oxford, Unpublished.

Plante, Thomas G., and Allen C. Sherman. 2001. Faith and Healthy: Psychological Perspectives. New York: The Guilford Press.

Rican, Pavel, and Pavlina Janosova. 2010. Spirituality as a basic aspect of personality: A cross-cultural verification of Piedmont's model. The International Journal for the Psychology of Religion 20: 2-13. [CrossRef]

Robertson, Theresa M., Awa Jangha, Ralph L. Piedmont, Martin F. Sherman, and Joseph E. G. Williams. 2017. Factor structure and personality disorder correlates of responses to the 50-item IPIP Big Five Factor Marker Scale. Journal of Social Research and Policy 8: 5-17.

Sinclair, S. J., C. J. Siefert, J. M. Slavin-Mulford, M.B. Stern, M. Renna, and M. A. Blais. 2012. Psychometric evaluation and mormative data for the depression, anxiety, and stress sscales-21 (DASS-21) in a nonclinical sample of U.S. adults. Evaluation $\mathcal{E}$ the Health Professions 35: 259-79. [CrossRef]

Sloan, Richard P., Emilia Bagiella, and Tia Powell. 2001. Without a prayer: Methodological problems, ethical challenges, and misrepresentations in the study of religion, spirituality, and medicine. In Faith and Health: Psychological Perspectives. Edited by Thomas Plante. New York: Guilford, pp. 339-54.

Tabachnick, Barbara G., Linda S. Fidell, and Jodie B. Ullman. 2007. Using Multivariate Statistics, 5th ed. Boston: Pearson Education.

Tillich, Paul. 2000. The Courage to Be, 2nd ed. New Haven: Yale University Press. First published 1952.

Toscano, Marion. E., Ralph. L. Piedmont, and Cynthia. E. Canner. 2017. Understanding Spiritual Transcendence as a Human Universal: Assessing Ultimate Meaning in Atheists and Agnostics. Paper presented at the Annual Convention of the Association of Spiritual, Ethical, and Religious Values in Counseling, Richmond, VA, USA, July 21.

Van Wicklin, John F. 1990. Conceiving and measuring ways of being religious. Journal of Psychology and Christianity 9: 27-40.

Voas, David. 2019. The Power of the Nones: Why Secularization Matters. Paper presented at the Deanna Kaplan (Covener) Religious Nones [Symposium]. Annual Meeting of the Society for the Scientific Study of Religion, St. Loius, MO, USA, October 25-27.

Voas, David, and Mark Chaves. 2016. Is the United States a counterexample to the secularization thesis? American Journal of Sociology 121: 1517-56. [CrossRef]

Wilt, Joshua A., Joshua B. Grubbs, Julie J Exline, and Kenneth I. Pargament. 2016. Personality, religious and spiritual struggles, and well-being. Psychology of Religion and Spirituality 8: 341-51. [CrossRef]

Publisher's Note: MDPI stays neutral with regard to jurisdictional claims in published maps and institutional affiliations. 